\title{
Geofísica
}

\section{para la prospección agrícola y forestal: guía para interpretar imágenes del subsuelo}

\section{Geophysics for agricultural and forestry surveying: guide to interpreting images of the underground}

\author{
Ulises Rodríguez-Robles ${ }^{1 *}$ y J. Tulio Arredondo Moreno ${ }^{2}$
}

\begin{abstract}
1 Universidad de Guadalajara. Centro Universitario de la Costa Sur. Departamento de Ecología y Recursos Naturales. Autlán, Jalisco, México.
\end{abstract}

2 Instituto Potosino de Investigación Científica y
Tecnológica. División de Ciencias Ambientales.
San Luis Potosí, San Luis Potosí, México. tulio@ipicyt.edu.mx
* Autor de correspondencia. ulises.rodriguez@cucsur.udg.mx

ulises.rodriguez@academicos.udg.mx

\section{RESUMEN}

La aplicación de técnicas de detección geofísica para mapear el subsuelo de campos agrícolas y forestales se ha acelerado en los últimos años. La obtención de imágenes geofísicas proporciona una alternativa o complemento a los métodos tradicionales para recopilar variables subsuperficiales a lo largo del tiempo y el espacio. Donde anteriormente el estándar era el muestreo de suelos y el análisis de laboratorio para evaluar la condición de un suelo para diversos propósitos, las técnicas de detección in situ están demostrando ser una forma muy efectiva para evaluar la variación de las propiedades del suelo / subsuelo. Este trabajo es una revisión del estado del arte relacionada con las técnicas geofísicas más aplicadas en la detección de las características y propiedades del subsuelo que influyen en la productividad y el funcionamiento de los ecosistemas forestales y sistemas agrícolas. En esta revisión se destacan las oportunidades, aplicaciones y retos que presentan las imágenes geofísicas (radargramas y tomogramas) en los campos multidisciplinarios de las biogeociencias. Las dos técnicas de investigación geofísica son muy atractivas para la comunidad científica, pues permiten mapear con precisión el subsuelo, graficar enraizamiento y monitorear contenidos de agua, identificar movimiento de sales y agroquímicos. Los agrónomos, silvicultores y la comunidad científica, podrían beneficiarse de la adopción de estas tecnologías de imágenes escalables y mínimamente invasivas para explorar el subsuelo y avanzar en nuestra investigación colectiva.

PALABRAS ClAVE: mapeo de raíces, métodos no-invasivos, radargramas, sistemas semi-áridos, técnicas geofísicas, tomogramas.

\section{ABSTRACT}

The application of geophysical detection techniques to mapping the underground of agricultural and forest fields has accelerated in recent years. Geophysical imaging provides an alternative or complement to traditional methods of collecting subsurface variables over time and space. Where previously the standard was soil sampling and laboratory analysis to assess the condition of a soil for its various purposes, in situ detection techniques are proving to be a very effective way to assess variation in soil / underground properties. This work is a review of the state of the art related to the most applied geophysical techniques in the detection of underground components and processes that can influence the productivity and functioning of forest ecosystems and agricultural systems. This review highlights the opportunities, applications and challenges presented by geophysical images (radargrams and tomograms) in the multidisciplinary fields of Biogeosciences. Both geophysical research techniques are very attractive to the scientific community, allowing the underground to be accurately mapped, plot rooting, monitor water content, identify sales movement and agrochemicals. Agronomists, foresters, and the scientific community would benefit from adopting these minimally invasive, scalable imaging technologies to the underground and advance our collective research.

KEYWORDS: root mapping, non-invasive methods, radargrams, semi-arid systems, geophysical techniques, tomograms. 


\section{INTRODUCCIÓN}

El potencial que tienen los métodos geofísicos para estudiar el subsuelo ha sido reconocido desde hace mucho tiempo, mostrando que pueden brindar ventajas competitivas muy importantes en el mercado con sus aplicaciones iniciales en la investigación de la estructura y el funcionamiento interno de la Tierra (Bruckshaw, 1948; Steeples, 2001). Dichos métodos incluyen tectonofísica, meteorología, oceanografía, física y sismología, que han tenido un uso intensivo por parte de la industria petrolera desde principios del siglo XX (Dezert, Fargier, Palma Lopes y Côte, 2019). Gracias a estos métodos, los estudios de arqueología ambiental, hidrogeología, ingeniería geotécnica y petrofísica se hicieron cada vez más comunes en 1970 (Diallo, Cheng, Rosa, Gunther y Chouteau, 2019; Paz, Alcalá, Carvalho y Ribeiro, 2017). De igual manera, también hubo alguna actividad de investigación agrícola de 1930 a 1945 relacionada con la medición de la humedad del suelo con métodos de resistividad eléctrica (Edlefsen y Anderson, 1941; Kirkham y Taylor, 1949), pero en su mayor parte, la aplicación de métodos geofísicos a la agricultura e ingeniería forestal no ganó impulso hasta la década de 1970 y 1980 , con el uso de métodos eléctricos y electromagnéticos para la evaluación de la salinidad del suelo y densidad de raíces (Halvorson y Rhoades, 1974; Read y Cameron, 1979; Tardieu, 1988).

Los métodos geofísicos pueden ser una herramienta importante, para el manejo y entendimiento de los procesos que ocurren en el subsuelo en el ámbito agrícola y forestal. Los desarrollos propuestos por la geofísica han incluido métodos eléctricos y electromagnéticos, como son las tomografías de resistividad eléctrica (ERT, por sus siglas en inglés) y el radar de penetración terrestre (GPR, por sus siglas en inglés), desarrollados para el monitoreo del agua, la evaluación de la salinidad y el mapeo del levantamiento del suelo (Butnor, Doolittle, Kress, Cohen y Johnsen, 2001; Chow y Rees, 1989; Halvorson y Rhoades, 1974; Vanderborght, Huisman, van der Kruk y Vereecken, 2013). En la actualidad, las aplicaciones agrícolas y forestales de los métodos geofísicos de ERT y GPR continúan aumentando rápidamente; además, otros métodos geofísicos, como la magnetometría y sísmica, ahora están comenzando a encontrar igualmente un uso en estas disciplinas (Bitella et al., 2015; Cimpoiasu, Kuras, Pridmore y Mooney, 2020).

\section{APLICACIONES Y PROFUNDIDAD EN LA INVESTIGACIÓN AGRÍCOLA Y FORESTAL}

La mayoría de los estudios geofísicos realizados en la industria petrolera tiene un interés en la profundidad de investigación inferior a $1 \mathrm{~km}$. (Bruckshaw, 1941; Jones, 2018). Por otra parte, la geofísica aplicada a la investigación hidrogeológica para determinar los recursos de agua subterránea y su conectividad, generalmente tienen interés a una profundidad no mayor a $250 \mathrm{~m}$ (Kelly y Mares, 1993; Sánchez-Higueredo et al., 2020; Senos Matias, Marques da Silva, Ferreira y Ramalho, 1994). Sin embargo, la prospección geofísica aplicada a las ciencias agrícolas y forestales varía drásticamente en escala con respecto a la profundidad de interés de la investigación. Hoy en día, existe una demanda creciente de tecnologías de prospección en la superficie para estudiar un amplio espectro de características y propiedades del suelo que tienen implicaciones en la agricultura y en las ciencias ambientales. Dichas implicaciones abarcan desde el análisis espacial y temporal del contenido de agua, hasta la detección de contaminantes, y desde el análisis de fertilidad y salinización del suelo, hasta el estudio de las interacciones suelo-raíz (Cassiani, Boaga, Vanella, Perri y Consoli, 2015).

En estudios de fisiología de cultivos y ecosistemas naturales, el entorno físico subterráneo considerado tradicionalmente, comprende la relación agua-suelo-plantaatmósfera (Nimah y Hanks, 1973; Tinker, 1976). En este contexto, la geofísica agrícola tiende a centrarse en gran medida en una zona de $2.5 \mathrm{~m}$ directamente debajo de la superficie del suelo, que incluye la zona de raíces y la mayor parte del perfil del suelo (Allred, Ehsani y Daniels, 2008; Liu, Dong y Leskovar, 2016). Los estudios de geofísica forestal, por otro lado, se centran a una profundidad máxima de $4 \mathrm{~m}$ del suelo; zona donde se obtiene mayor información de los recursos de agua y nutrientes que los 
árboles adquieren y movilizan a lo largo de todo el perfil (Bitella et al., 2015; Jones, Cassidy, Thomas, Plante y Pringle, 2009; Zenone et al., 2008) y que no solo incluye el suelo, sino también el lecho de roca degradada química y físicamente (roca intemperizada), donde la rizosfera se extiende comúnmente (Dawson, Hahm y Crutchfield-Peters, 2020; Rodriguez-Robles, Arredondo, Huber-Sannwald, RamosLeal y Yepez, 2017).

A menudo las técnicas geofísicas se usan en combinación, porque en la fase de interpretación la ambigüedad que surge de los resultados de un método de detección se puede resolver en función de los resultados de otro método (Rodriguez-Robles et al., 2017; Vanderborght et al., 2013). Los tomogramas (ERT) y radargramas (GPR) —dos técnicas de imágenes geofísicas - tienen un sustancial futuro en el campo agrícola y forestal. Estas técnicas ofrecen información de varios procesos físicos que afectan la estructura del suelo en múltiples escalas espaciales y temporales (Corwin y Scudiero, 2019; Freeland, Yoder y Ammons, 1998; Allred, Freeland, Farahani y Collins, 2010), y brindan pautas para la identificación de mecanismos biológicos, al vincular la geodiversidad con las características hidrológicas del sustrato rocoso y la ecología de raíces (Rodriguez-Robles et al., 2017; Schwinning, 2010).

Atinadamente, las imágenes geofísicas han recibido una atención creciente en los últimos años dentro de la comunidad científica gracias a su carácter no destructivo y su capacidad para proporcionar información sobre las características del subsuelo en grandes áreas (Morari, Castrignano y Pagliarin, 2009; Pawlik y Kasprzak, 2018). Los agrónomos, silvicultores, ecólogos, fisiólogos y ecohidrólogos necesitan información detallada sobre la salud vegetal, las propiedades y procesos del suelo incluidos los cambios en el nivel freático-, las sales y otros elementos que pueden influir en la productividad y el funcionamiento de los ecosistemas y sistemas agrícolas (Piccoli, Furlan, Lazzaro y Morari, 2019). En suma, la ERT y el GPR son dos técnicas de investigación muy atractivas para la comunidad científica, que permiten mapear con precisión el subsuelo; graficar enraizamiento, monitorear flujos subterráneos y contenidos de agua, identificar movimiento de sales, agroquímicos y zonas de infiltración, sin generar perturbaciones (Tabla 1).

\section{PRINCIPIOS DE LAS TÉCNICAS GEOFÍSICAS}

Los métodos geofísicos son una herramienta emergente que involucra técnicas no invasivas para tener información valiosa de las condiciones o características del subsuelo y la superficie cercana. Todos los métodos geofísicos miden indirectamente las distribuciones de propiedades físicas del subsuelo (Jayawickreme, Jobbagy y Jackson, 2014; Tosti, Patriarca, Slob, Benedetto y Lambot, 2013). La tomografía de resistividad eléctrica (ERT) utiliza un campo eléctrico de baja frecuencia para determinar la estructura de resistividad eléctrica del subsuelo y el radar de penetración terrestre (GPR) utiliza ondas electromagnéticas de alta frecuencia que son sensibles a la permitividad dieléctrica de un material del substrato (Leucci, Margiotta y Negri, 2004; Ward, 1987). Los datos generalmente se obtienen sobre la superficie del suelo, pero - a diferencia de la mayoría de las técnicas de detección remota-, los datos geofísicos contienen información sobre la variabilidad en las propiedades del subsuelo.

\section{Tomografías de Resistividad Eléctrica, ERT}

$\mathrm{El}$ principio de funcionamiento de la ERT es la inyección de una corriente eléctrica conocida en el subsuelo a través de un conjunto de electrodos de transmisión y en la posterior medición de la diferencia de voltaje con un conjunto de electrodos receptores. La ERT del subsuelo se basa en variabilidad de la resistencia a la conductancia de la corriente eléctrica (Corwin y Lesch, 2005), la cual diferirá en materiales subsuperficiales, dependiendo de las variaciones en el contenido de humedad, densidad y composición química. De esta manera, los tomogramas ERT pueden proporcionar información sobre la distribución espacial de la resistividad eléctrica (es decir, la conductividad eléctrica) en el subsuelo (Walter, Luck, Heller, Bauriegel y Zeitz, 2019). 
TABLA 1. Aplicaciones potenciales de las técnicas de tomografías de resistividad eléctrica (ERT) y radar de penetración terrestre (GPR) en el campo agrícola y forestal.

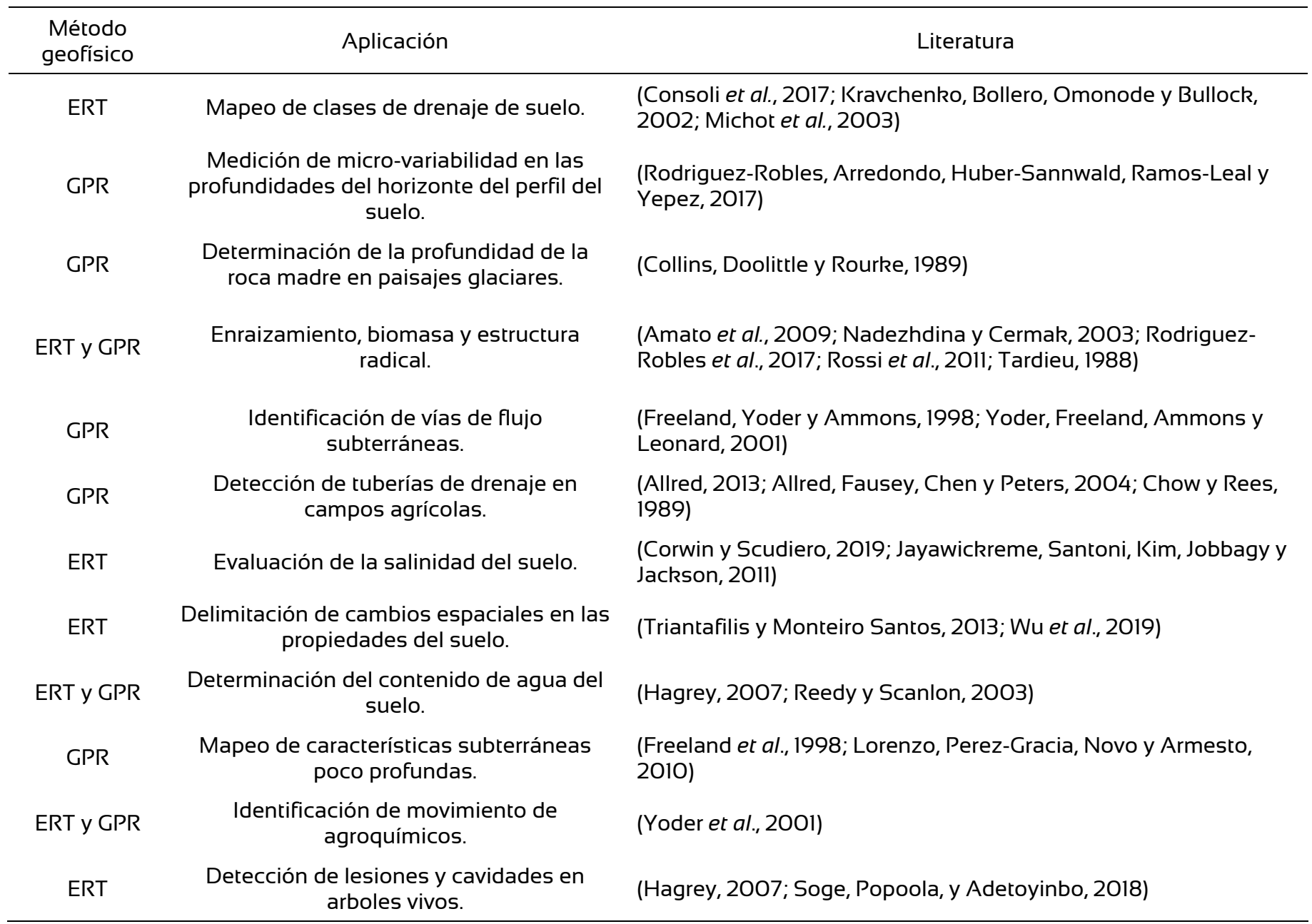

El estudio de imágenes ERT se lleva acabo utilizando una distribución de electrodos a lo largo de perfiles individuales colocados en la superficie externa del terreno a explorar. La separación y el número de electrodos dependen del tamaño del área de estudio y la resolución requerida. A medida que aumenta el espaciado entre electrodos, aumenta la profundidad de penetración y disminuye la resolución efectiva de la imagen (tomograma ERT). La resistividad eléctrica en la mayoría de los suelos disminuye con el incremento del contenido de agua en el poro, la salinidad (contenido iónico y movilidad) y la conductividad hidráulica, así como la temperatura (que reduce la viscosidad y aumenta la movilidad iónica) (Allred, Ehsani y Daniels, 2008; Ward, 1987). En zonas agrícolas y forestales con matriz muy resistiva, los suelos conducen electricidad a través de los electrolitos del agua intersticial o tisular (Akpan, Ilori y Essien, 2015; Ward, 1987).

\section{Radar de Penetración Terrestre, GPR}

El GPR por su parte, es una técnica electromagnética utilizada para detectar cambios en las propiedades físicas del subsuelo de baja profundidad, operando dentro de frecuencias de $20 \mathrm{MHz}$ a $2.5 \mathrm{GHz}$. Una unidad GPR consta de tres componentes básicos: la unidad de control (incluido 
el generador de impulsos, la computadora y el software asociado), las antenas blindadas (incluidas el par de antenas de transmisión y recepción) y la unidad de visualización (Hirano et al., 2008). Durante la detección del GPR, la energía electromagnética de alta frecuencia, generada al transmitir la antena, se propaga por el suelo en forma de ondas. Cuando las ondas del GPR atraviesan interfaces entre medios con diferentes propiedades eléctricas o magnéticas, se generan reflexiones y una parte de la energía reflejada de nuevo en la superficie, será registrada por la antena receptora (Butnor et al., 2001). Las ondas reflejadas se combinan en una traza de reflexión, registrando el tiempo de viaje en dos sentidos; es decir, el tiempo transcurrido entre la emisión y la detección de la señal reflejada. Los datos recopilados en tiempo real pueden manipularse en información detallada que proporcione la profundidad, orientación y tamaño de las características del subsuelo (Cui et al., 2011). La profundidad de penetración y la resolución dependen de la longitud de onda y de la frecuencia del método GPR aplicado a una amplia gama de problemas agrícolas, como el mapeo de la geometría de la raíz de la planta y el mapeo rápido del contenido de agua del suelo (Tabla 1). Otro uso potencial de imágenes GPR podría ser para ubicar tuberías de plástico de drenaje agrícola enterradas. La profundidad de penetración de la señal del GPR y el tamaño mínimo en el que se puede detectar un objeto están inversamente relacionados con la frecuencia de la antena empleada. Las antenas GPR de baja frecuencia $(50 \mathrm{MHz}-250 \mathrm{MHz})$ son mejores para ubicar objetos más grandes (tuberías de $30 \mathrm{~cm}$ de diámetro) y profundamente enterrados $(10 \mathrm{~m}-20 \mathrm{~m})$, y las antenas GPR de alta frecuencia (entre $1 \mathrm{GHz}$ y $2.3 \mathrm{GHz}$ ) son más aplicables para objetos pequeños (tuberías de $3 \mathrm{~cm}$ a $5 \mathrm{~cm}$ ) y poco profundos $(0.1 \mathrm{~m}-0.3 \mathrm{~m})$, en gran medida la resolución y la profundidad de la investigación va a depender de las características dieléctricas del suelo. Una implicación importante con respecto a los problemas de profundidad de la investigación y detección es utilizar los GPR con la configuración adecuada, que proporcione una profundidad de investigación similar a la profundidad de interés (Barton y Montagu, 2004).
USO POTENCIAL AGRÍCOLA Y FORESTAL PARA LAS IMÁGENES GEOFÍSICAS: RADARGRAMASGPR Y TOMOGRAMAS-ERT

En el 2000, los métodos y herramientas geofísicas seguían siendo difíciles de acceder para usos más rutinarios debido a los altos costos de los equipos y la dificultad de las campañas de prospección, así como a la escasez de instrumentación adecuada para las mediciones superficiales del subsuelo. Los avances recientes en electrónica e instrumentación, adquisición y procesamiento de datos y visualización e interpretación de imágenes han reducido muchas de las limitaciones anteriores. A pesar de la necesidad de disponer de datos superficiales del subsuelo, la comunidad agrícola y forestal se ha mantenido en su mayoría sin conocimiento de los avances recientes en imágenes geofísicas que pueden beneficiar en gran medida su producción y el entendimiento de fenómenos ecológicos que se detonan en el subsuelo (Mares, Barnard, Mao, Revil y Singha, 2016; Rodriguez-Robles et al., 2017; Yoder, Freeland, Ammons y Leonard, 2001). Como profesionales estamos llamados a buscar estrategias que permitan superar los grandes retos, siendo clave para esto la incorporación de nuevas tecnologías que amplíen la visión integral del fenómeno de estudio. Las técnicas como el GPR y ERT pueden transcender cualquier campo, desde las biogeociencias hasta las ciencias forenses (Barone y Di Maggio, 2019; Cermak, Nadezhdina, Trcala y Simon, 2015; Khaldaoui, Djeddi, Zagh y Naa, 2017). Las aplicaciones de las imágenes geofísicas en las que los tomogramas-ERT y radargramas-GPR pueden proporcionar información valiosa para fines agrícolas y forestales se enlistan en la tabla 1.

En el texto a continuación se analiza el impacto y la sensibilidad que pueden tener estas dos tecnologías en la agricultura y en el campo forestal para comprender procesos ecohidrológicos. Se utilizaron como zona de estudio los biomas de pastizal y bosque semiárido, en donde se utilizaron imágenes de tomografías-ERT, para evaluar los cambios de humedad en el perfil del suelo y los radargramas-GPR, para identificar la distribución de raíces por árboles en un sustrato rocoso poco profundo. 


\section{Pastizal semiárido}

Los cultivos agrícolas anuales a menudo tienen raíces poco profundas y, a diferencia de las especies nativas, no pueden extraer agua con bajo potencial mátrico (Canadell et al., 1996). Así, con temporadas de crecimiento más cortas y otras diferencias de los cultivos en comparación con la vegetación semiárida, como los pastizales naturales, permitiría que no se utilice un mayor volumen de humedad del suelo (Boenecke, Lueck, Ruehlmann, Gruendling y Franko, 2018). De esta manera, la agricultura en entornos semiáridos puede conducir al inicio del drenaje de aguas profundas en el suelo (Fernández-Cirelli, Arumí, Rivera y Boochs, 2009). Por lo tanto, se necesita cada vez más información espacial de la distribución de las raíces de las plantas y de los volúmenes de agua almacenados en suelo, para comprender y gestionar el comportamiento de los cultivos.

La sensibilidad de la resistividad eléctrica o la conductividad por el contenido de agua puede explotarse para explorar muchos fenómenos ecológicos y agronómicos (Jayawickreme et al., 2014; Rodriguez-Robles et al., 2017). En la agricultura, los métodos ERT y GPR se han propuesto como una técnica no destructiva para cuantificar y mapear la biomasa de las raíces, pero se necesita evidencia sobre la aplicabilidad de la técnica a baja densidad de raíces en cultivos agrícolas.

En un estudio de caso, realizado en parcelas de maízfrijol ubicadas en la estación de investigación Vaquerías del Instituto Nacional de Investigaciones Forestales, Agrícolas y Pecuarias en el municipio de Ojuelos, Jalisco, México

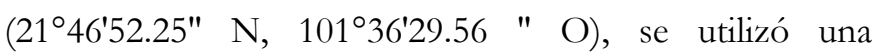
combinación de técnicas (ERT y GPR) para resaltar la variación de la resistividad / contenido de agua. A lo largo de un transecto de $22 \mathrm{~m}$ de distancia que cruzaba seis parcelas de $2.0 \mathrm{~m} \times 2.0 \mathrm{~m}$ se realizó un levantamiento de resistividad 2D (SYSCAL KID SWITCH-24, IRIS instruments) con una matriz Wenner-Schlumberger con 46 electrodos alineados en la superficie del suelo y una separación de electrodos de $0.5 \mathrm{~m}$. Además, se realizó un levantamiento GPR en la misma línea con un equipo de georradar (MALÅ RAMAC X3M GPR - ProEx system) con una antena de $800 \mathrm{MHz}$ acoplado a una rueda de inspección (odómetro).

En la sección ERT 2D la resistividad osciló entre $10 \Omega \mathrm{m}$ y $60 \Omega$ m hasta una profundidad de $2.5 \mathrm{~m}$. Los valores de resistividad más altos ( $40 \Omega \mathrm{m}$ a $60 \Omega \mathrm{m}$ ) se asociaron a la presencia de raíces activas que mantienen bombeo de agua de la capa del suelo, desecándolo en los primeros $80 \mathrm{~cm}$ (color rojo - naranja). Por el contrario, los valores más bajos $(10 \Omega \mathrm{m}$ a $39 \Omega \mathrm{m})$ podrían atribuirse a un mayor contenido de agua y / o presencia de arcilla (color azul - gris, Fig. 1). Las imágenes ERT en las parcelas 5 y 6 (a los $16 \mathrm{~m}$ y a los $22 \mathrm{~m}$ de distancia en transecto) muestran la resistividad más baja con valores de $11 \Omega \mathrm{m}$. Esta sección es un área control desprovista de vegetación que contrasta con el resto de las parcelas por existir una tasa de pérdida menor de agua (i.e. evapotranspiración) que en el resto (Figs. 1c-d y 2c-d). La imagen GPR correspondiente al perfil ERT (Fig. 3) exhibe una mayor atenuación de la señal hiperbólica en el lado derecho y esto puede estar asociado al aumento del agua en el suelo y a la falta de raíces. La imagen GPR ayudó a interpretar la distribución espacial de las raíces en las parcelas, así como los perfiles del sustrato. Se puede observar en los primeros $35 \mathrm{~cm}$ de profundidad, un perfil con bastante ruido, debido a la labranza del suelo dentro de las parcelas. Algunas dificultades en la interpretación de los radares crudos (perfiles de radar sin filtrar) incluyen el ruido y las áreas fantasma causadas por las características de los suelos removidos (Hirano et al., 2008). Sin embargo, la imagen GPR muestra claras reflexiones hiperbólicas que corresponden a la posición de las raíces de las plantas, validadas con excavaciones a ciertas profundidades (ver círculos, Fig. 3).

La figura 2 muestra una imagen ERT que fue levantada al día siguiente, tras un evento de precipitación de $21 \mathrm{~mm}$, se puede observar detalladamente las zonas de mayor infiltración y cómo va cambiando la resistividad del suelo (56 $\Omega \mathrm{m}$ a $22 \Omega \mathrm{m}$ ), las regiones de mayor humedad se marcan en azul. Por otra parte, la imagen ERT 3D correspondiente al perfil ERT (Fig. 4) muestra cortes a cada $25 \mathrm{~cm}$ de profundidad en la que se muestran perfiles horizontales de la sumatoria de los cuatro perfiles que 
conforma la figura 2. En los primeros $25 \mathrm{~cm}$ se observa mayor variabilidad en los valores de resistividad, debido a las zonas de mayor evaporación y sumideros de agua, a diferencia del perfil más profundo $(125 \mathrm{~cm}-150 \mathrm{~cm})$ donde los valores más bajos de resistividad se asocian a las zonas de retención de humedad por infiltración y flujos horizontales. Por lo tanto, como en toda exploración geofísica la interpretación de la imagen requiere de una calibración en el terreno (Barton y Montagu, 2004)

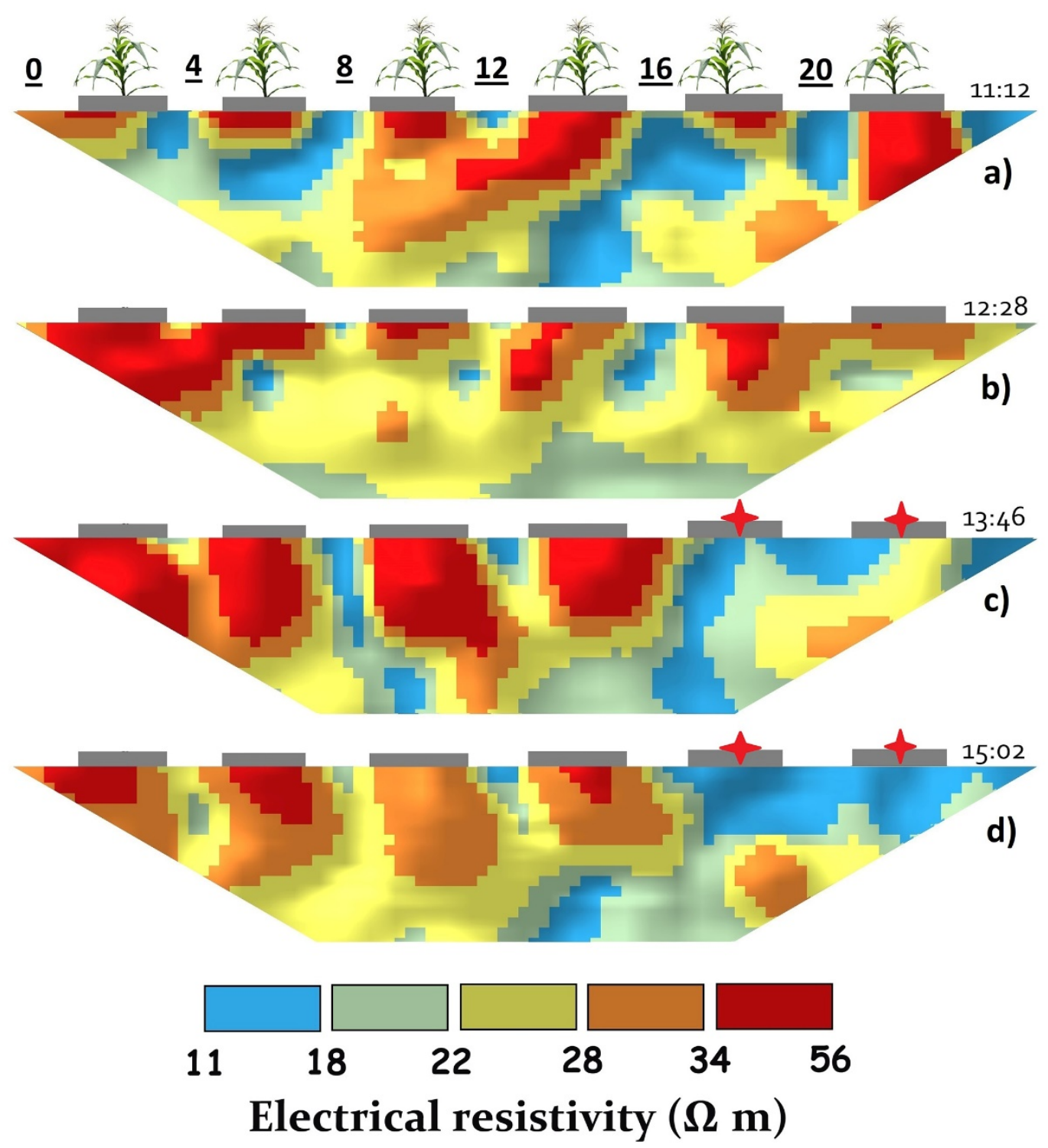

FIgURA 1. Tomogramas ERT en parcelas experimentales de $2 \mathrm{~m} \times 2 \mathrm{~m}$ a lo largo de un transecto de $23 \mathrm{~m}$ con un perfil de suelo de $2.5 \mathrm{~m}$ de profundidad.

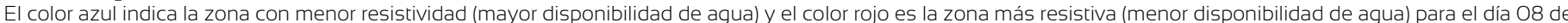

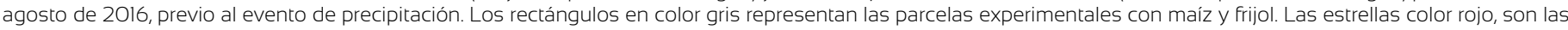
parcelas control. 


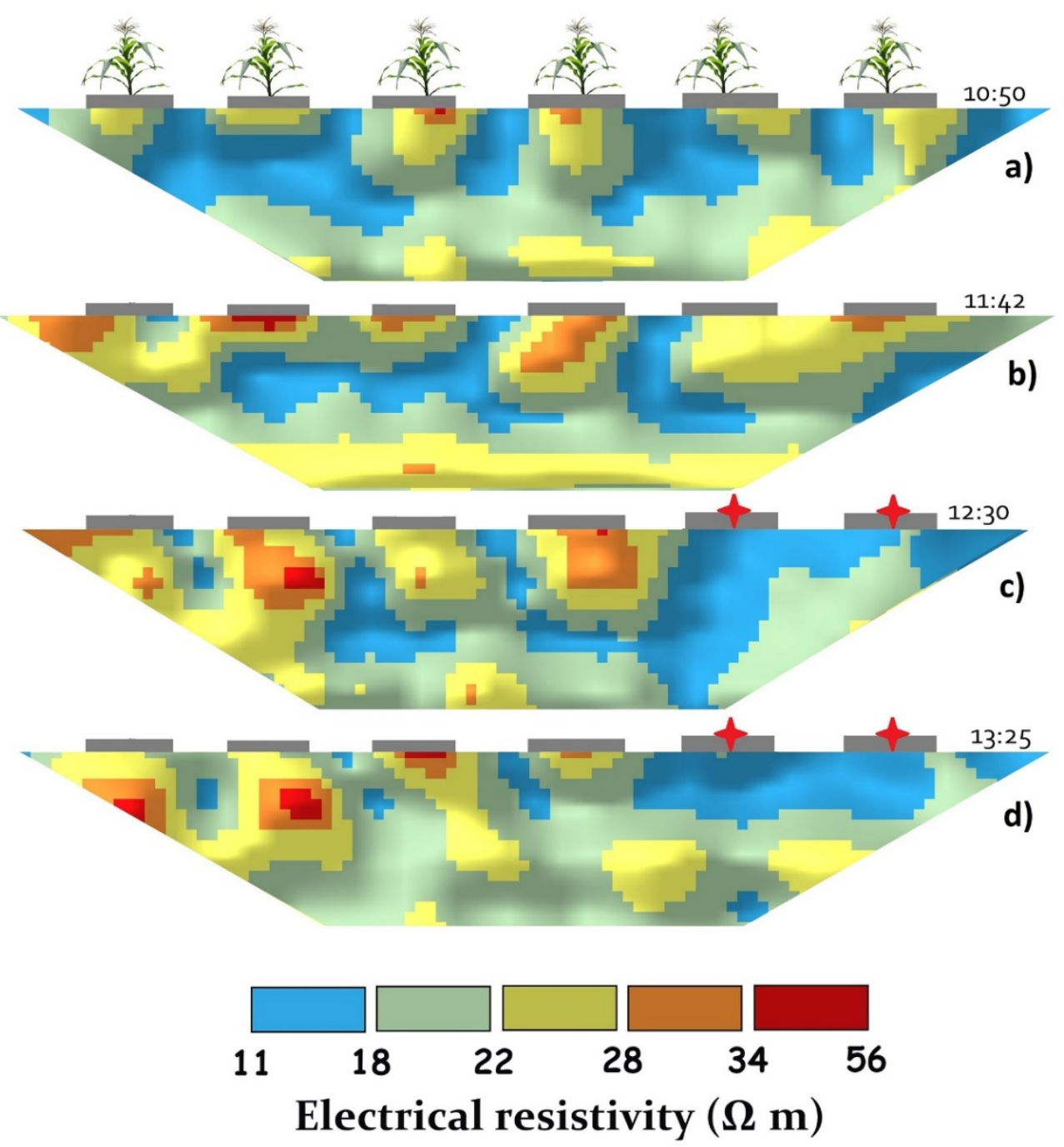

FIGURA 2. Tomogramas ERT en parcelas experimentales de $2 \mathrm{~m} \times 2 \mathrm{~m}$ a lo largo de un transecto de $23 \mathrm{~m}$ con un perfil de suelo de $2.5 \mathrm{~m}$ de profundidad.

El color azul indica la zona con menor resistividad (mayor disponibilidad de agua) y el color rojo es la zona más resistiva (menor disponibilidad de agua) para el día 09 de agosto de 2016, posterior a un evento de precipitación de $21 \mathrm{~mm}$. Los rectángulos en color gris representan las parcelas experimentales con maíz y frijol. Las estrellas color rojo, son las parcelas control.

En la última década, los sensores geofísicos basados en la medición no destructiva de la conductividad eléctrica del suelo (o su resistividad inversa) se han utilizado ampliamente en la agricultura de precisión (Boenecke $e t$ al., 2018; Corwin y Lesch, 2005). Las imágenes ERT y GPR usadas en la investigación del subsuelo de baja profundidad, permiten elaborar una cartografía espacio temporal de la humedad mediante secciones horizontales y verticales para su mejor interpretación (Lunt, Hubbard y Rubin, 2005). A través del uso adecuado del agua y de fertilizantes, los rendimientos de las cosechas pueden optimizarse y la agricultura se vuelve menos dependiente de los patrones de precipitación (Jayawickreme, Santoni, Kim, Jobbagy y Jackson, 2011). Cuando se conjuntan ambos tipos de imágenes geofísicas para su interpretación se puede conocer la distribución de las raíces (diámetro, profundidad, elongación) y la ubicación de la capa freática o zonas de humedad, ajustando la dosis de fertilizantes de acuerdo con la cantidad de agua disponible en el suelo (von Hebel et al., 2014; Yoder et al., 2001). 


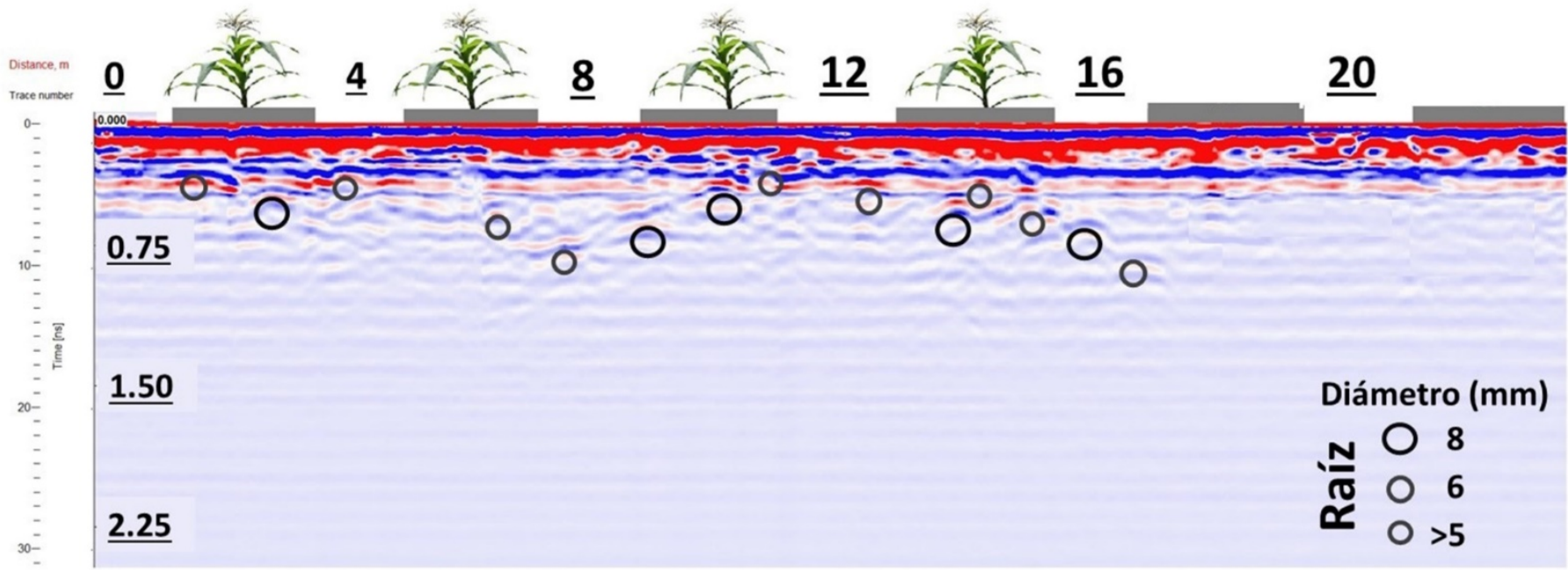

FIGURA 3. Distribución espacial de raíces (sección transversal) de Zea mays y Phaseolus vulgaris L. a lo largo de un transecto de monitoreo de $23 \mathrm{~m}$ con un perfil de suelo de $2.25 \mathrm{~m}$ de profundidad.

El radargrama GPR se generó con una antena blindada de $800 \mathrm{MHz}$ y filtros de paso de banda para eliminar el ruido de baja y alta frecuencia. Los reflejos en forma hiperbólica representan los reflectores de las raíces. Los círculos de diferentes tamaños representan raíces de diferente diámetro. Seis raíces que fueron excavadas para la calibración del radargrama GPR. El radargrama y tomograma (perfil de la figura ld) mostraron una relación entre la posición de las raíces y la alta resistividad del suelo (menor disponibilidad de agua). Los rectángulos en color gris representan las parcelas experimentales de $2 \mathrm{~m} \times 2$ m con maíz y frijol

\section{Bosque tropical semiárido}

Los nichos hidrológicos determinan qué especies pueden coexistir en ambientes semiáridos y cómo responden las especies a eventos hidrológicos extremos como la sequía. Un componente importante del nicho hidrológico implica la división de las fuentes de agua, pero en paisajes caracterizados por suelos poco profundos sobre lechos de roca fracturada, el crecimiento de las raíces está altamente limitado (Poot, Hopper y van Diggelen, 2012). Se ha sugerido que las marcadas diferencias en los patrones de enraizamiento entre especies sirven como adaptaciones que minimizan la competencia por el agua durante períodos prolongados cuando no ocurre precipitación y las capas superiores del suelo se vuelven extremadamente secas (Brassard, Chen y Bergeron, 2009; David et al., 2013). Generalmente se piensa que los suelos poco profundos son restrictivos para el crecimiento vertical de las raíces porque a menudo cubren el lecho rocoso consolidado impidiendo que el agua del suelo y las raíces se trasladen hacia abajo (Poot \& Lambers, 2008); se sabe muy poco sobre la distribución de las raíces que crecen bajo este tipo de suelo, lo cual principalmente se debe a las dificultades de excavación (Estrada-Medina, Tuttle, Graham, Allen y Jimenez-Osornio, 2010). Así, en el caso de las raíces gruesas de los árboles generalmente se examinan utilizando métodos de excavación (por ejemplo, zanjas y trincheras de sistemas de raíces) (Schroth y Kolbe, 1994; Tennant, 1975). Mientras que las raíces finas se han estudiado mediante técnicas de muestreo secuencial de núcleos de suelo y con el uso de núcleos de crecimiento libre de raíces (Dornbush, Isenhart y Raich, 2002; Welbank y Williams, 1968; Yuan y Chen, 2013).

Para explorar el potencial de los métodos geofísicos, se utilizó como caso de estudio un ecosistema forestal en la Sierra de San Miguelito (SSM), San Luis Potosí, México. La SSM divide los ecosistemas áridos de matorrales hacia el norte y el bioma de pastizal semiárido hacia el sur (22.044388 N, -101.126643 O). Como la presencia y el éxito del bosque en este sitio no pueden explicarse en términos de condiciones climáticas, se implementó el GPR con una 

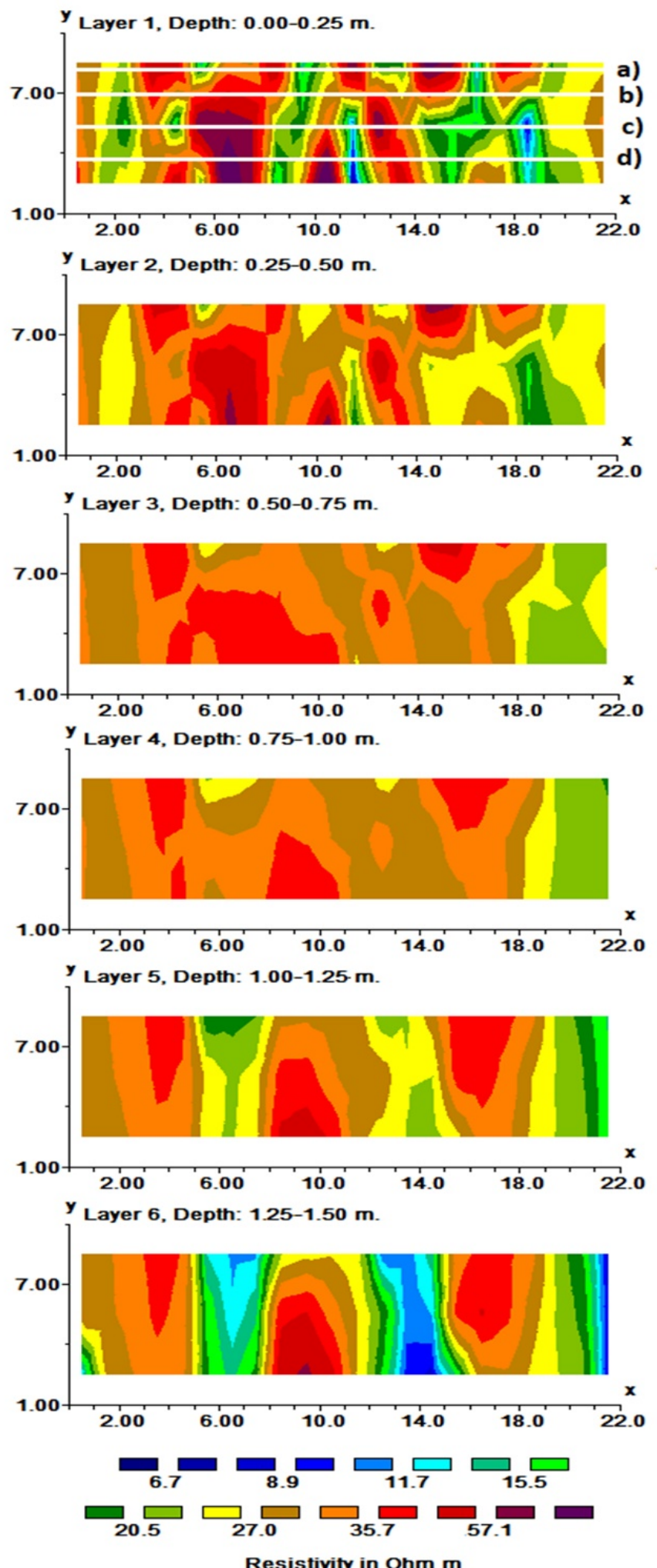

FIGURA 4. Tomograma ERT en secciones 3D del terreno para la caracterización de la capa del suelo cultivable.

Imagen en capas del subsuelo obtenida mediante barridos con perfiles separados de $2 \mathrm{~m}$. Las secciones de los perfiles a, b, c y d (líneas color blanco) corresponden a los perfiles de las figuras 1 y 2. Los seis cortes transversales de la imagen ERT 3D, muestran una profundidad promedio de $25 \mathrm{~cm}$. Error de predicción (error estándar promedio) de $17.5 \%$. Espaciamiento entre electrodos: $X=\operatorname{lm}$ y $Y=3 m$. 
gama de antenas blindadas de diferentes frecuencias (50 $\mathrm{MHz}, 250 \mathrm{MHz}$ y $500 \mathrm{MHz}$ ) para identificar las condiciones geológicas que pueden explicar la presencia de este bosque. La SSM es un macizo montañoso de rocas volcánicas impermeables, altamente degradado por procesos de exfoliación (desprendimiento en láminas), caracterizado por suelos poco profundos $(<25 \mathrm{~cm})$. A pesar de los suelos delgados, el complejo volcánico de la SSM sostiene una compleja vegetación de bosque tropical semiárido con presencia de pinos y encinos (Rodríguez-Robles, Arredondo, Huber-Sannwald y Vargas, 2015). Estudios recientes sugieren que las especies arbóreas nativas pueden tener la capacidad de extraer agua del lecho rocoso subterráneo (Proust et al., 2011; Querejeta, Estrada-Medina, Allen, Jimenez-Osornio y Ruenes, 2006; Schwinning, 2013); sin embargo, la mayoría de estos estudios se centran en sitios de roca permeable (por ejemplo, calizas).

Los radargramas-GPR derivados de la antena de 50 $\mathrm{MHz}$ diferenciaron una capa de $0.25 \mathrm{~m}$ que correspondía al suelo poco profundo (Fig. 5a), con afloramientos rocosos en la superficie (p. ejemplo, 5 m, 12 m, 41 m, 45 m). Debajo de esta capa, los radargramas exhibieron una capa altamente fracturada con depósitos de tierra dispersos y regolitos debido a la meteorización de las rocas (entre $0.25 \mathrm{~m}$ y 0.75 $\mathrm{m})$. Más allá de $0.75 \mathrm{~m}$, el radargrama-GPR mostró material de roca fresca de varios metros de espesor, sin fisuras ni grietas. Sin embargo, cuando se usó la antena de $250 \mathrm{MHz}$ y una serie de rutinas de procesamiento como eliminación de fondo y la migración de Stolt FK, se pudo observar placas curvas desprendidas derivadas de costras de rocas subterráneas (rocas exfoliadas como producto de procesos de meteorización mecánica) y la distribución de las raíces leñosas gruesas debajo de las rocas exfoliadas (Figs. 5b, c).

Los radargramas-GPR con la antena de $500 \mathrm{MHz}$ (Fig. 5d), el filtrado de paso de banda y la eliminación de fondo permitieron delinear y ubicar raíces en el suelo rocoso $(0 \mathrm{~m}-0.45 \mathrm{~m})$. Las hipérbolas de estas raíces se hicieron visibles y la amplitud de las ondas reflejadas disminuyó al disminuir el diámetro de la raíz (Fig. 5d). Las raíces detectadas con GPR en los diferentes rodales se validaron y calibraron en el campo (Fig. 5e), mostrando diámetros de $2.5 \mathrm{~cm}$ a $7.5 \mathrm{~cm}$ a una profundidad máxima de $40 \mathrm{~cm}$. Los rodales de Pinus cembroides mostraron mayor número de raíces gruesas (458 raíces, $\varnothing>6 \mathrm{~cm}$ ) a diferencia de los radales de Quercus potosina, que mostraron el mayor número de raíces en la clase de menor diámetro (412 raíces, Ø $2.5-3 \mathrm{~cm}$, Tabla 2). La evidencia de la distribución del agua se puede ver en la figura $5 \mathrm{f}$, donde las zonas de húmedas marcadas en color azul ocurren a $50 \mathrm{~cm}$ y debajo de la roca exfoliada (Fig. 5b).

Finalmente, se analizó la distribución espacial de las raíces para los diferentes rodales, se muestra que el diámetro de la raíz tendía a aumentar a medida que aumentaba la profundidad del suelo en el caso de los rodales de pino puro (Figs. 6a, b). En contraste, el diámetro de las raíces, en los rodales de encinos puros, tienden a disminuir a medida que aumenta la profundidad del suelo (Figs. 6c, d), mientras que en los rodales mixtos observamos una tendencia a la disminución del diámetro en las raíces más profundas (Figs. 6e, f).

Los resultados sugieren que la presencia de roca exfoliada en estos sistemas forestales con suelos poco profundos $(<25 \mathrm{~cm})$ puede contribuir a satisfacer la demanda de agua, sirviendo como zona de suministro. Por un lado, el encino especializado en la exploración de capas más profundas se abastece de agua almacenada en la roca fracturada; mientras que el pino se abastece de agua de las bolsas de suelo existentes entre las rocas. De esta manera, pino y encino se adaptan ante eventos hidrológicos extremos como la sequía. Así, la diferencia en la distribución de las raíces determina dónde pueden persistir las especies; asegurando la coexistencia de Pinus. cembroides y Quercus potosina. 

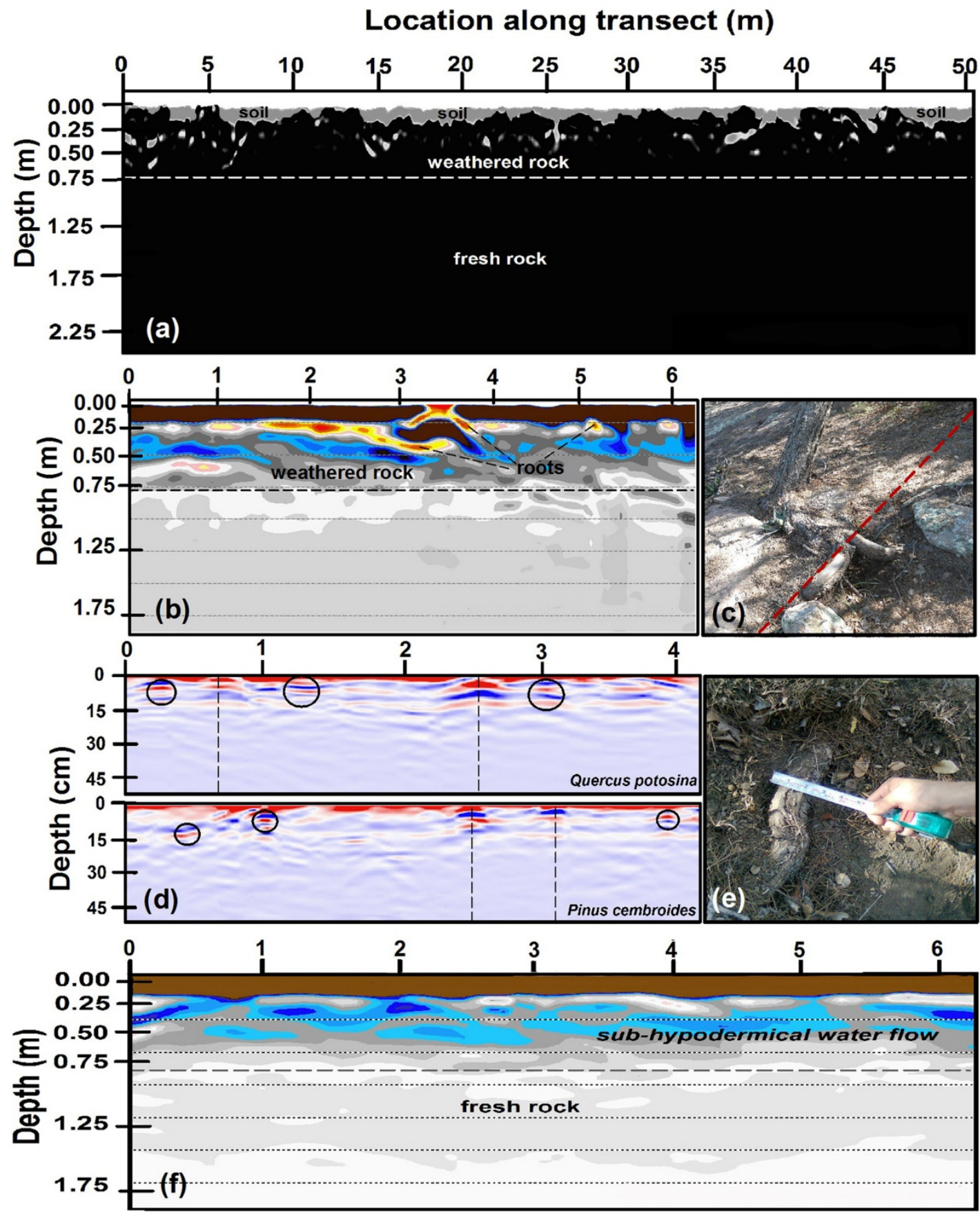

FIGURA 5. Radargramas GPR: (a) sistema GPR con una antena blindada de frecuencia de $50 \mathrm{MHz}$ utilizada para identificar la profundidad del suelo y las rocas meteorizadas, (b) sistema GPR con una antena blindada de frecuencia de $250 \mathrm{MHz}$ y migración Stolt FK, utilizada para detectar la distribución de raíces leñosas debajo de rocas exfoliadas, (c) fotografía in situ, que muestra la raíz leñosa gruesa de Quercus potosina anclada en rocas exfoliadas, (d) sistema GPR con una antena blindada de frecuencia de $500 \mathrm{MHz}$, aplicando filtros de paso de banda (filtro de paso alto y filtro de paso bajo) para eliminar ambos ruidos de baja y alta frecuencia.

Los reflejos de forma hiperbólica representan los reflectores raíz. Los tamaños de los círculos son indicativos de diferentes tamaños de diámetro de las raices y las líneas

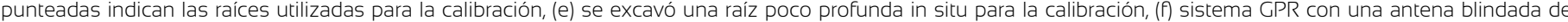
frecuencia de $250 \mathrm{MHz}$, el área azul se refiere a la zona de mayor humedad en la interfaz de la roca erosionada y suelo. 
TABLA 2. Número total de raíces detectadas y diámetro medio de raíz para cada clase diamétrica en rodales monoespecíficos de Pinus cembroides y Quercus potosina y rodales mixtos de pino-encino, estimadas a partir de radargramas-GPR.

\begin{tabular}{|c|c|c|c|c|c|c|c|c|c|}
\hline & \multicolumn{3}{|c|}{ Pinus cembroides } & \multicolumn{3}{|c|}{ Quercus potosina } & \multicolumn{3}{|c|}{ Bosque mixto } \\
\hline $\begin{array}{l}\text { Clase } \\
\text { diamétrica } \\
(\mathrm{cm})\end{array}$ & $\begin{array}{l}\text { Raíces } \\
\text { detec- } \\
\text { tadas }^{a}\end{array}$ & $\begin{array}{c}\text { Transectos } \\
\text { en los que se } \\
\text { encontraron } \\
\text { raíces }^{b}\end{array}$ & Media $\pm S E^{c}$ & $\begin{array}{l}\text { Raices } \\
\text { dectec- } \\
\text { tadas }^{a}\end{array}$ & $\begin{array}{c}\text { Transectos } \\
\text { en los que se } \\
\text { encontraron } \\
\text { raíces }^{b}\end{array}$ & Media $\pm S E^{\complement}$ & $\begin{array}{l}\text { Raices } \\
\text { dectec- } \\
\text { tadas }^{a}\end{array}$ & $\begin{array}{l}\text { Transectos en } \\
\text { los que se } \\
\text { encontraron } \\
\text { raíces }^{b}\end{array}$ & Media $\pm \mathrm{SE}^{\mathrm{c}}$ \\
\hline $2.5-3.0$ & 204 & 16 & $2.65 \pm 0.05$ & 412 & 16 & $2.63 \pm 0.12$ & 500 & 16 & $2.65 \pm 0.12$ \\
\hline $3.0-3.5$ & 36 & 16 & $3.28 \pm 0.01$ & 56 & 16 & $3.28 \pm 0.36$ & 27 & 12 & $3.28 \pm 0.07$ \\
\hline $3.5-4.0$ & 19 & 15 & $3.92 \pm 0.01$ & 43 & 14 & $3.87 \pm 0.14$ & 104 & 16 & $3.92 \pm 0.15$ \\
\hline $4.0-4.5$ & 13 & 4 & $4.63 \pm 0.44$ & 19 & 7 & $4.25 \pm 0.08$ & 16 & 6 & $4.13 \pm 0.50$ \\
\hline $4.5-5.0$ & 103 & 13 & $4.58 \pm 0.02$ & 122 & 9 & $4.55 \pm 0.11$ & 169 & 13 & $4.60 \pm 0.08$ \\
\hline $5.0-5.5$ & 12 & 4 & $5.23 \pm 0.02$ & 17 & 9 & $5.20 \pm 0.68$ & 62 & 16 & $5.22 \pm 0.08$ \\
\hline $5.5-6.0$ & 17 & 13 & $5.88 \pm 0.01$ & 23 & 14 & $5.84 \pm 0.03$ & 53 & 15 & $5.84 \pm 0.26$ \\
\hline$>6.0$ & 458 & 8 & $7.57 \pm 0.97$ & 160 & 13 & $7.67 \pm 0.87$ & 573 & 14 & $7.61 \pm 1.00$ \\
\hline $\begin{array}{l}\text { Todas las } \\
\text { clases }\end{array}$ & 862 & 16 & $4.71 \pm 1.54$ & 852 & 16 & $4.66 \pm 1.58$ & 1504 & 16 & $4.65 \pm 1.56$ \\
\hline
\end{tabular}

\section{RETOS, OPORTUNIDADES Y APLICACIONES INNOVADORAS}

Los nuevos desarrollos en la geofísica están en curso como métodos innovadores, equipos y rutinas de campo. Lo mismo está ocurriendo para la geofísica agrícola y forestal. $\mathrm{Al}$ igual que todas las herramientas de investigación, se debe de cumplir con algunas condiciones básicas para aplicar las técnicas geofísicas a los campos de estudio. La profundidad de sondeo y el tamaño de la característica a detectar son dos cuestiones importantes que deben tenerse en cuenta al decidir sobre el equipo a utilizar y su configuración. Normalmente hay una compensación entre la profundidad en la investigación y el tamaño mínimo que debe tener una característica para ser detectada.

Por otra parte, la profundidad de sondeo y la resolución van a depender no solo de la física del método sino también de la distribución de las propiedades del subsuelo. Estas características incluyen rangos compatibles de características de campo, una buena correspondencia entre el método de obtención de imágenes y la información subsuperficial buscada, la capacidad de obtener datos geofísicos de alta calidad, la disponibilidad de esquemas adecuados de procesamiento e inversión de datos y la posibilidad de vincular respuestas geofísicas a variables subsuperficiales de interés. Una advertencia adicional con imágenes geofísicas es que pueden sobre interpretarse para extraer conclusiones incorrectas o poco realistas. Por lo tanto, los esfuerzos por integrar imágenes geofísicas para la investigación en los diferentes campos de investigación se deben hacer entre geofísicos y las disciplinas de interés.

Motivados por nuestra experiencia con las técnicas geofísicas, pensamos que el crecimiento continuo de las investigaciones emergentes conducirá a nuevos descubrimientos para las disciplinas que convergen en las biogeociencias. Muchos conceptos y fenómenos ecológicos que se prueban e inician en la actualidad como son la integración de la zona crítica terrestre para el estudio de la ecofisiología de plantas (Dawson et al., 2020), así como los mecanismos que impulsan el proceso de muerte y decadencia masas forestales (Allen, Breshears y McDowell, 2015; Brantley et al., 2017), por mencionar algunos, eventualmente se convertirán en un lugar común para la detección geofísica. 


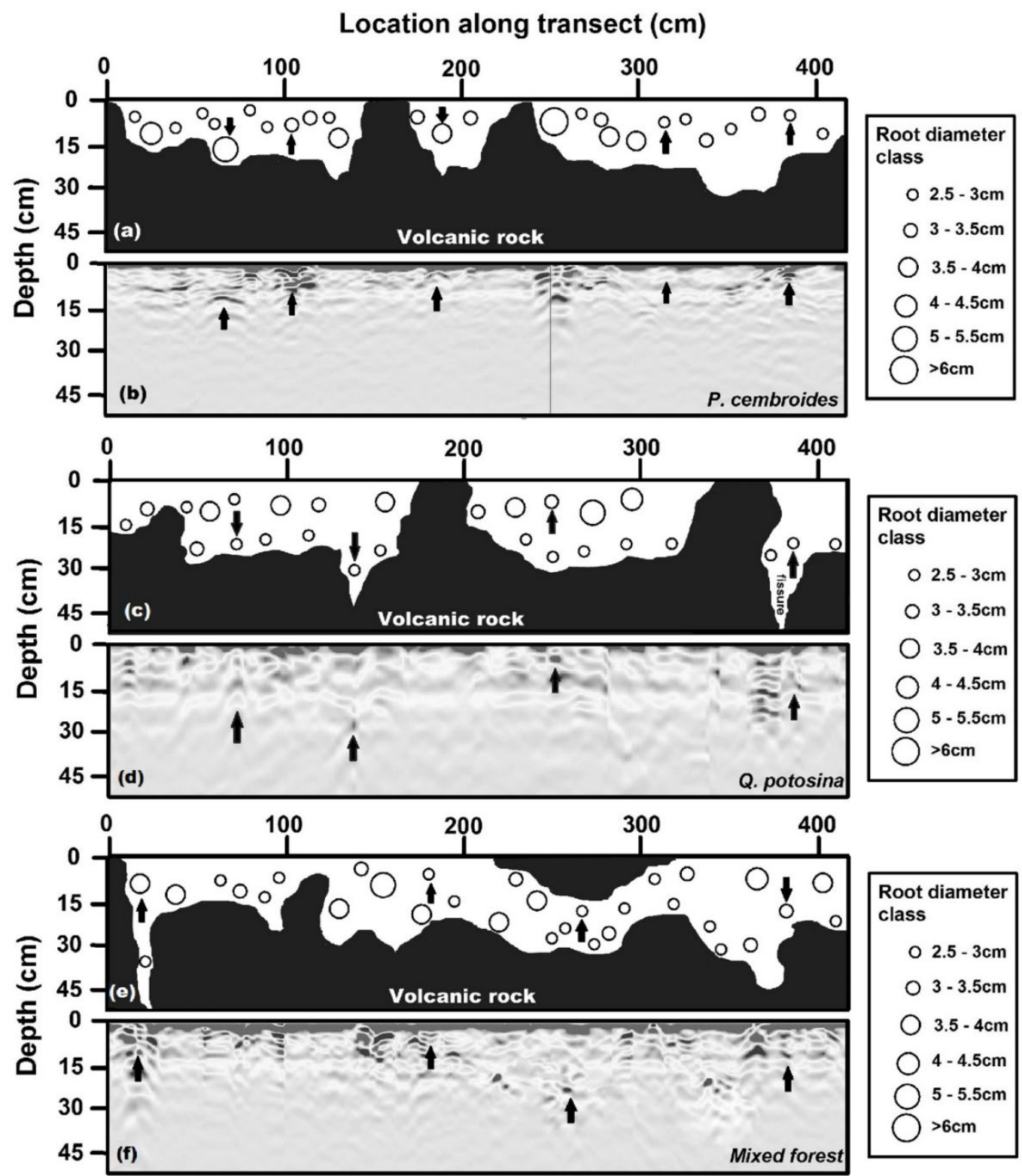

FiguRA 6. Distribución vertical de raíces de (a) Pinus cembroides, (c) Quercus potosina, (d) rodales mixtos a lo largo de un transecto. Los reflejos de forma hiperbólica representan los reflectores de las raíces. En negro se representa la roca volcánica. Los radargramas GPR de las raíces después del filtro de eliminación de fondo ( $\mathrm{b}$, d y f). Las flechas negras indican raíces que se detectaron para la calibración de GPR.

\section{CONCLUSIONES}

La incorporación de métodos geofísicos no empleados en el pasado para fines agrícolas y forestales encontrará un uso significativo en el futuro. Los métodos geofísicos que probablemente incursionarán en las ciencias forestales incluyen la magnetometría y sísmica. También pueden existir oportunidades agrícolas para otros métodos, como la resonancia magnética, la polarización inducida y electro- magnética VFL. Esto ayudaría a aliviar el cuello de botella tecnológico para las investigaciones del subsuelo; por ejemplo, a comprender nichos geoespaciales que predominan en la supervivencia de las plantas en periodos de sequía prolongados. Para ello, se necesitará una mayor interacción entre geofísicos, ecólogos, forestales y agrónomos para afinar estos métodos. 


\section{RECONOCIMIENTOS}

Los autores desean expresar su sincero agradecimiento al financiamiento de los proyectos: "El papel de escenarios experimentales de cambio climático en la agricultura de temporal de regiones semiáridas: evaluación de incrementos de temperatura y reducción de precipitación en el rendimiento y desempeño de frijol y maíz de temporal (SEP-CB-2013-220788)", "La mortandad forestal global, identificando las condiciones ambientales y los mecanismos fisiológicos que disparan mortandad forestal masiva en bosques semiáridos y templados del centro de México (FC2016-1811)". Así como su gratitud al apoyo brindado por las bibliotecas; Antonio a la Torre del Centro Universitario de la Costa Sur, Universidad de Guadalajara y Ramfis Ayús Reyes de El Colegio de la Frontera Sur, Villahermosa.

\section{REFERENCIAS}

Akpan, A. E., Ilori, A. O., \& Essien, N. U. (2015). Geophysical investigation of Obot Ekpo Landslide site, Cross River State, Nigeria. Journal of African Earth Sciences, 109, 154-167. doi: 10.1016/j.jafrearsci.2015.05.015

Allen, C. D., Breshears, D. D., \& McDowell, N. G. (2015). On underestimation of global vulnerability to tree mortality and forest die-off from hotter drought in the Anthropocene, 6(8), 1-55. doi:10.1890/es15-00203.1

Allred, B. (2013). A GPR Agricultural Drainage Pipe Detection Case Study: Effects of Antenna Orientation Relative to Drainage Pipe Directional Trend. Journal of Environmental \& Engineering Geophysics, 18(1), 55-69. doi: 10.2113/JEEG18.1.55

Allred, B. J., Fausey, N. R., Chen, C.-C., Peters, L., Youn, H.-S., \& Daniels, J. F. (2004). GPR detection of drainage pipes in farmlands, (Vol. 1). Proceedings of the Tenth International Conference on Grounds Penetrating Radar, 2004, Delft, Netherlands, 2 May 2004. Washington, USA: IEEE Corporate Communications.

Allred, B., Daniels, J. J., \& Ehsani, M. R. (Eds.). (2008). General Considerations for Geophysical Methods Applied to Agriculture. Handbook of Agricultural Geophysics. 14 pp. Boca Ratón. USA: CRC Press. doi: 10.1201/9781420019353

Allred, B. J., Freeland, R. S., J. Farahani, H. J., \& Collins, M. E. (2010). Agricultural Geophysics: Past, Present, and Future. Conference Proceedings, 23 ${ }^{\text {rd }}$ EEGS Symposium on the Application of Geophysics to Engineering and Environmental Problems, April 2010, cp 175-00023: European Association of Geoscientists \& Engineers. doi: 10.3997/2214-4609-pdb.175.SAGEEP023
Amato, M., Bitella, G., Rossi, R., Gómez, J. A., Lovelli, S., \& Gomes, J. J. F. (2009). Multi-electrode 3D resistivity imaging of alfalfa root zone. European Journal of Agronomy, 31(4), 213-222. doi: 10.1016/j.eja.2009.08.005

Barone, P. M., \& Di Maggio, R. M. (2019). Forensic geophysics: ground penetrating radar (GPR) techniques and missing persons investigations. Forensic Sciences Research, 4(4), 337-340. doi: 10.1080/20961790.2019.1675353

Barton, C. V., \& Montagu, K. D. (2004). Detection of tree roots and determination of root diameters by ground penetrating radar under optimal conditions. Tree Physiol, 24(12), 1323-1331. doi: $10.1093 /$ treephys/24.12.1323

Bitella, G., Rossi, R., Loperte, A., Satriani, A., Lapenna, V., Perniola, M., \& Amato, M. (2015). Geophysical Techniques for Plant, Soil, and Root Research Related to Sustainability. En A. Vastola (Ed.), The Sustainability of Agro-Food and Natural Resource Systems in the Mediterranean Basin (pp. 353-372). Cham: Springer International Publishing. doi: 10.1007/978-3-319-16357-4_23

Boenecke, E., Lueck, E., Ruehlmann, J., Gruendling, R., \& Franko, U. (2018). Determining the within-field yield variability from seasonally changing soil conditions. Precision Agriculture, 19(4), 750-769. doi: 10.1007/s11119-017-9556-z

Brantley, S. L., Eissenstat, D. M., Marshall, J. A., Godsey, S. E., BaloghBrunstad, Z., Karwan, D. L., Papuga, S. A., Roering, J., Dawson, T. E., Evaristo, J., Chadwick, O., McDonnell, J., \& Weathers, K. C. (2017). Reviews and syntheses: on the roles trees play in building and plumbing the critical zone. Biogeosciences, 14(22), 5115-5142. doi: 10.5194/bg-14-5115-2017

Brassard, B. W., Chen, H. Y. H., \& Bergeron, Y. (2009). Influence of Environmental Variability on Root Dynamics in Northern Forests. Critical Reviews in Plant Sciences, 28(3), 179-197. doi: 10.1080/07352680902776572

Bruckshaw, J. McG. (1941). Geophysical Prospecting for Oil. Nature, 148(3745), 151-152. doi: 10.1038/148151a0

Bruckshaw, J. M. (1948). The application of geophysics to geology. Proceedings of the Geologists' Association, 59(3), 113-130,IN1-IN13. doi: 10.1016/S0016-7878(48)80015-5

Butnor, J. R., Doolittle, J. A., Kress, L., Cohen, S., \& Johnsen, K. H. (2001). Use of ground-penetrating radar to study tree roots in the southeastern United States. Tree Physiology, 21(17), 1269-1278.

Canadell, J., Jackson, R. B., Ehleringer, J. B., Mooney, H. A., Sala, O. E., \& Schulze, E. D. (1996). Maximum rooting depth of vegetation types at the global scale. Oecologia, 108(4), 583-595. doi: 10.1007/bf00329030 
Cassiani, G., Boaga, J., Vanella, D., Perri, M. T., \& Consoli, S. (2015). Monitoring and modelling of soil-plant interactions: the joint use of ERT, sap flow and eddy covariance data to characterize the volume of an orange tree root zone. Hydrology and Earth System Sciences, 19(5), 2213-2225. doi: 10.5194/hess-19-2213-2015

Cermák, J., Nadezhdina, N., Trcala, M., \& Simon, J. (2015). Open fieldapplicable instrumental methods for structural and functional assessment of whole trees and stands. Iforest-Biogeosciences and Forestry, 8(3), 226-278. doi: 10.3832/ifor1116-008

Chow, T. L., \& Rees, H. W. (1989). Identification of subsurface drain locations with ground-penetrating radar. Canadian Journal of Soil Science, 69(2), 223-234. doi: 10.4141/cjss89-023

Cimpoiasu, M. O., Kuras, O., Pridmore, T., \& Mooney, S. J. (2020). Potential of geoelectrical methods to monitor root zone processes and structure: A review. Geoderma, 365. doi: 10.1016/j.geoderma.2020.114232

Collins, M. E., Doolittle, J. A., \& Rourke, R. V. (1989). Mapping Depth to Bedrock on a Glaciated Landscape with Ground-Penetrating Radar. Soil Science society of America Journal, 53(6), 1806-1812. doi: 10.2136/sssaj1989.03615995005300060032x

Consoli, S., Stagno, F., Vanella, D., Boaga, J., Cassiani, G., \& Roccuzzo, G. (2017). Partial root-zone drying irrigation in orange orchards: Effects on water use and crop production characteristics. European Journal of Agronomy, 82(A), 190-202. doi: 10.1016/j.eja.2016.11.001

Corwin, D. L., \& Lesch, S. M. (2005). Apparent soil electrical conductivity measurements in agriculture. Computers and Electronics in Agriculture, 46(1-3), 11-43. doi: 10.1016/j.compag.2004.10.005

Corwin, D. L., \& Scudiero, E. (2019). Review of soil salinity assessment for agriculture across multiple scales using proximal and/or remote sensors. En D. L. Sparks (Ed.), Advances in Agronomy, Vol 158 (pp. 1-130). Incluir ciudad, país: editorial.

Cui, X., Chen, J., Shen, J., Cao, X., Chen, X., \& Zhu, X. (2011). Modeling tree root diameter and biomass by ground-penetrating radar. Science China Earth Sciences, 54(5), 711-719. doi: 10.1007/s11430010-4103-z

David, T. S., Pinto, C. A., Nadezhdina, N., Kurz-Besson, C., Henriques, M. O., Quilhó, T., Cermak, J., Chaves, M. M., Pereira. J. S., \& David, J. S. (2013). Root functioning, tree water use and hydraulic redistribution in Quercus suber trees: A modeling approach based on root sap flow. Forest Ecology and Management, 307, 136-146. doi: 10.1016/j.foreco.2013.07.012

Dawson, T. E., Hahm, W. J., \& Crutchfield-Peters, K. (2020). Digging deeper: what the critical zone perspective adds to the study of plant ecophysiology. 226(3), 666-671. doi: 10.1111/nph.16410
Dezert, T., Fargier, Y., Palma Lopes, S., \& Côte, P. (2019). Geophysical and geotechnical methods for fluvial levee investigation: A review. Engineering Geology, 260, 105206. doi: 10.1016/j.enggeo.2019.105206

Diallo, M. C., Cheng, L. Z., Rosa, E., Gunther, C., \& Chouteau, M. (2019). Integrated GPR and ERT data interpretation for bedrock identification at Cléricy, Québec, Canada. Engineering Geology, 248, 230-241. doi: 10.1016/j.enggeo.2018.09.011

Dornbush, M. E., Isenhart, T. M., \& Raich, J. W. (2002). Quantifying Fine-Root Decomposition: An Alternative to Buried Litterbags. Ecology, 83(11), 2985-2990. doi: 10.2307/3071834

Edlefsen, N. E., \& Anderson, A. B. C. (1941). The four-electrode resistance method for measuring soilmoisture content under field conditions. Soil Science, 51(5), 367-376.

Estrada-Medina, H., Tuttle, W., Graham, R. C., Allen, M. F., \& JimenezOsornio, J. J. (2010). Identification of Underground Karst Features using Ground-Penetrating Radar in Northern Yucatan, Mexico. Vadose Zone Journal, 9(3), 653-661. doi: 10.2136/vzj2009.0116

Fernández-Cirelli, A., Arumí, J. L., Rivera, D., \& Boochs, P. W. (2009). Environmental Effects of Irrigation in Arid and Semi-Arid Regions. J Chilean journal of agricultural research, 69, 27-40.

Freeland, R. S., Yoder, R. E., \& Ammons, J. T. (1998). Mapping shallow underground features that influence site-specific agricultural production. Journal of Applied Geophysics, 40(1-3), 19-27. doi: 10.1016/s0926-9851(98)00014-7

Hagrey, S. A., al (2007). Geophysical imaging of root-zone, trunk, and moisture heterogeneity. Journal of Experimental Botany, 58(4), 839854. doi:10.1093/jxb/erl237

Halvorson, A. D., \& Rhoades, J. D. (1974). Assessing Soil Salinity and Identifying Potential Saline-Seep Areas with Field Soil Resistance Measurements. 38(4), 576-581. doi: 10.2136/sssaj1974.03615995003800040018x

Hirano, Y., Dannoura, M., Aono, K., Igarashi, T., Ishii, M., Yamase, K., Makita, N. \& Kanazawa, Y. (2008). Limiting factors in the detection of tree roots using ground-penetrating radar. Plant and Soil, 319(1), 15. doi: 10.1007/s11104-008-9845-4

Jayawickreme, D. H., Jobbagy, E. G., \& Jackson, R. B. (2014). Geophysical subsurface imaging for ecological applications. New Phytologist, 201(4), 1170-1175. doi: 10.1111/nph.12619

Jayawickreme, D. H., Santoni, C. S., Kim, J. H., Jobbagy, E. G., \& Jackson, R. B. (2011). Changes in hydrology and salinity accompanying a century of agricultural conversion in Argentina. Ecological Applications, 21(7), 2367-2379. doi: 10.1890/10-2086.1 
Jones, C. M. (2018). The oil and gas industry must break the paradigm of the current exploration model. Journal of Petroleum Exploration and Production Technology, 8(1), 131-142. doi: 10.1007/s13202-0170395-2

Jones, G. M., Cassidy, N. J., Thomas, P. A., Plante, S., \& Pringle, J. K. (2009). Imaging and monitoring tree-induced subsidence using electrical resistivity imaging. Near Surface Geophysics, 7(3), 191-206. doi: 10.3997/1873-0604.2009017

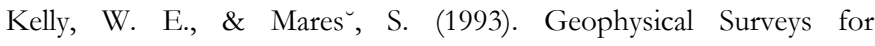
Hydrogeological Purposes. En W. E. Kelly \& S. Mares (Eds.), Developments in Water Science (Vol. 44, pp. 31-99). Lincoln, NE, USA: Elsevier.

Khaldaoui, F., Djeddi, M., Zagh, A., \& Naa, A. Use of near-surface geophysical methods for forensic investigations. In International Conference on Engineering Geophysics, Al Ain, United Arab Emirates, 912 October 2017 (pp. 216-219).

Kirkham, D., \& Taylor, G. S. (1949). Some Tests of a FourElectrode Probe for Soil Moisture Measurement. Soil Science of America Journal, 14(C), 42-46. doi: 10.2136/sssaj1950.036159950014000C0010x

Kravchenko, A., Bollero, G., Omonode, R. A., \& Bullock, D. (2002). Quantitative Mapping of Soil Drainage Classes Using Topographical Data and Soil Electrical Conductivity. Soil Science Society of America Journal, 66(1), 235-243. doi: $10.2136 /$ sssaj2002.0235

Leucci, G., Margiotta, S., \& Negri, S. (2004). Geophysical and geological investigations in a karstic environment (Salice Salentino, Lecce, Italy). Journal of Environmental and Engineering Geophysics, 9(1), 25-34. doi: $10.4133 /$ jeeg 9.1 .25

Liu, X. W., Dong, X. J., \& Leskovar, D. I. (2016). Ground penetrating radar for underground sensing in agriculture: a review. International Agrophysics, 30(4), 533-543. doi: 10.1515/intag-2016-0010

Lorenzo, H., Perez-Gracia, V., Novo, A., \& Armesto, J. (2010). Forestry applications of ground-penetrating radar. Forest Systems, 19(1), 517. doi: 10.5424/fs/2010191-01163

Lunt, I. A., Hubbard, S. S., \& Rubin, Y. (2005). Soil moisture content estimation using ground-penetrating radar reflection data. Journal of Hydrology, 307(1-4), 254-269. doi: 10.1016/j.jhydrol.2004.10.014

Mares, R., Barnard, H. R., Mao, D. Q., Revil, A., \& Singha, K. (2016). Examining diel patterns of soil and xylem moisture using electrical resistivity imaging. Journal of Hydrology, 536, 327-338. doi: 10.1016/j.jhydrol.2016.03.003

Michot, D., Benderitter, Y., Dorigny, A., Nicoullaud, B., King, D., \& Tabbagh, A. (2003). Spatial and temporal monitoring of soil water content with an irrigated corn crop cover using surface electrical resistivity tomography. Water Resources Research, 39(5), 1-20. doi: 10.1029/2002wr001581

Morari, F., Castrignano, A., \& Pagliarin, C. (2009). Application of multivariate geostatistics in delineating management zones within a gravelly vineyard using geo-electrical sensors. Computers and Electronics in Agriculture, 68(1), 97-107. doi: 10.1016/j.compag.2009.05.003

Nadezhdina, N., \& Čermák, J. (2003). Instrumental methods for studies of structure and function of root systems of large trees. Journal of Experimental Botany, 54(387), 1511-1521. doi: 10.1093/jxb/erg154

Nimah, M. N., \& Hanks, R. J. (1973). Model for Estimating Soil Water, Plant, and Atmospheric Interrelations: I. Description and Sensitivity. Soil Science Society of America Journal, 37(4), 522-527. doi: 10.2136/sssaj1973.03615995003700040018x

Pawlik, L., \& Kasprzak, M. (2018). Regolith properties under trees and the biomechanical effects caused by tree root systems as recognized by electrical resistivity tomography (ERT). Geomorphology, 300, 1-12. doi: 10.1016/j.geomorph.2017.10.002

Paz, C., Alcalá, F. J., Carvalho, J. M., \& Ribeiro, L. (2017). Current uses of ground penetrating radar in groundwater-dependent ecosystems research. Science of the Total Environment, 595, 868-885. doi: 10.1016/j.scitotenv.2017.03.210

Piccoli, I., Furlan, L., Lazzaro, B., \& Morari, F. (2019). Examining conservation agriculture soil profiles: Outcomes from northeastern Italian silty soils combining indirect geophysical and direct assessment methods. European Journal of Soil Science, 71(6), 1064-1075. doi: 10.1111/ejss.12861

Poot, P., Hopper, S. D., \& van Diggelen, J. M. (2012). Exploring rock fissures: does a specialized root morphology explain endemism on granite outcrops? Annals of Botany, 110(2), 291-300. doi: $10.1093 / \mathrm{aob} / \mathrm{mcr} 322$

Poot, P., \& Lambers, H. (2008). Shallow-soil endemics: adaptive advantages and constraints of a specialized root-system morphology. New Phytologist, 178(2), 371-381. doi: 10.1111/j.1469-8137.2007.02370.x

Proust, D., Caillaud, J., Fontaine, C., Fialin, M., Courbe, C., \& Dauger, N. (2011). Fissure and mineral weathering impacts on heavy metal distribution in sludge-amended soil. Plant and Soil, 346(1-2), 2944. doi: 10.1007/s11104-011-0791-1

Querejeta, J. I., Estrada-Medina, H., Allen, M. F., Jimenez-Osornio, J. J., \& Ruenes, R. (2006). Utilization of bedrock water by Brosimum alicastrum trees growing on shallow soil atop limestone in a dry tropical climate. Plant and Soil, 287(1-2), 187-197. doi: 10.1007/s11104-006-9065-8 
Read, D. W. L., \& Cameron, D. R. (1979). Relationship between salinity and Wenner resistivity for some dryland soils. Canadian Journal of Soil Science, 59(4), 381-385. doi: 10.4141/cjss79-043

Reedy, R. C., \& Scanlon, B. R. (2003). Soil Water Content Monitoring Using Electromagnetic Induction. Journal of Geotechnical and Geoenvironmental Engineering, 129(11), 1028-1039. doi: 10.1061/(ASCE)1090-0241(2003)129:11(1028)

Rodríguez-Robles, U., Arredondo, J. T., Huber-Sannwald, E., \& Vargas, R. (2015). Geoecohydrological mechanisms couple soil and leaf water dynamics and facilitate species coexistence in shallow soils of a tropical semiarid mixed forest. New Phytologist, 207(1), 59-69. doi: $10.1111 /$ nph.13344

Rodriguez-Robles, U., Arredondo, T., Huber-Sannwald, E., Ramos-Leal, J. A., \& Yepez, E. A. (2017). Technical note: Application of geophysical tools for tree root studies in forest ecosystems in complex soils. Biogeosciences, 14(23), 5343-5357. doi: 10.5194/bg14-5343-2017

Rossi, R., Amato, M., Bitella, G., Bochicchio, R., Gomes, J. J. F., Lovelli, S., Martorella, P. \& Favale, P. (2011). Electrical resistivity tomography as a non-destructive method for mapping root biomass in an orchard. European Journal of Soil Science, 62(2), 206215. doi: 10.1111/j.1365-2389.2010.01329.x

Sánchez-Higueredo, L. E., Ramos-Leal, J. A., Morán-Ramírez, J., Moreno-Casasola Barceló, P., Rodríguez-Robles, U., \& Hernández Alarcón, M. E. (2020). Ecohydrogeochemical functioning of coastal freshwater herbaceous wetlands in the Protected Natural Area, Ciénaga del Fuerte (American tropics): Spatiotemporal behaviour. Ecohydrology, 13(2), e2173. doi: $10.1002 /$ eco. 2173

Schroth, G., \& Kolbe, D. (1994). A method of processing soil core samples for root studies by subsampling. Biology and Fertility of Soils, 18(1), 60-62. doi: 10.1007/BF00336446

Schwinning, S. (2010). The ecohydrology of roots in rocks. Ecobydrology, 3(2), 238-245. doi: 10.1002/eco.134

Schwinning, S. (2013). Do we need new rhizosphere models for rockdominated landscapes? Plant and Soil, 362(1-2), 25-31. doi: $10.1007 /$ s11104-012-1482-2

Senos Matias, M., Marques da Silva, M., Ferreira, P., \& Ramalho, E. (1994). A geophysical and hydrogeological study of aquifers contamination by a landfill. Journal of Applied Geophysics, 32(2), $155-$ 162. doi: 10.1016/0926-9851(94)90017-5

Soge, A., Popoola, O., \& Adetoyinbo, A. (2018). Detection of decay and hollows in living almond trees (Terminalia catappa L. Roxb.) using electrical resistivity method. Journal of the Indian Academy of Wood Science, 15(2), 181-189. doi: 10.1007/s13196-018-0224-3
Steeples, D. (2001). Engineering and environmental geophysics at the millennium. Geophysics, 66, 31-35. doi: 10.1190/1.1444910

Tardieu, F. (1988). Analysis of the spatial variability of maize root density. Plant and Soil, 107(2), 267-272. doi: 10.1007/BF02370556

Tennant, D. (1975). A Test of a Modified Line Intersect Method of Estimating Root Length. Journal of Ecology, 63(3), 995-1001. doi: $10.2307 / 2258617$

Tinker, P. B. (1976). Transport of Water to Plant Roots in Soil. Philosophical Transactions of the Royal Society of London-Series B, Biological Sciences, 273(927), 445-461.

Tosti, F., Patriarca, C., Slob, E., Benedetto, A., \& Lambot, S. (2013). Clay content evaluation in soils through GPR signal processing. Journal of Applied Geophysics, 97, 69-80. doi: 10.1016/j.jappgeo.2013.04.006

Triantafilis, J., \& Monteiro Santos, F. A. (2013). Electromagnetic conductivity imaging (EMCI) of soil using a DUALEM-421 and inversion modelling software (EM4Soil). Geoderma, 211-212, 2838. doi: doi.org/10.1016/j.geoderma.2013.06.001

Vanderborght, J., Huisman, J. A., van der Kruk, J., \& Vereecken, H. (2013). Geophysical Methods for Field-Scale Imaging of Root Zone Properties and Processes. En S. H. Anderson \& J. W. Hopmans (Eds.), Soil-Water-Root Processes: Advances in Tomography and Imaging (Vol. 61, pp. 247-282). Madison, WI, USA: Soil Science Society of America, Inc.

von Hebel, C., Rudolph, S., Mester, A., Huisman, J. A., Kumbhar, P., Vereecken, H., \& van der Kruk, J. (2014). Three-dimensional imaging of subsurface structural patterns using quantitative largescale multiconfiguration electromagnetic induction data. Water Resources Research, 50(3), 2732-2748. doi: 10.1002/2013wr014864

Walter, J., Luck, E., Heller, C., Bauriegel, A., \& Zeitz, J. (2019). Relationship between electrical conductivity and water content of peat and gyttja: implications for electrical surveys of drained peatlands. Near Surface Geophysics, 17(2), 169-179. doi: 10.1002/nsg.12030

Ward, S. H. (1987). Electrical Methods in Geophysical Prospecting. En C. G. Sammis \& T. L. Henyey (Eds.), Methods in Experimental Physics (Vol. 24, pp. 265-375). Los Angeles, CA, USA: Academic Press.

Welbank, P. J., \& Williams, E. D. (1968). Root Growth of a Barley Crop Estimated by Sampling with Portable Powered Soil-Coring Equipment. Journal of Applied Ecology, 5(2), 477-481. doi: $10.2307 / 2401574$

Wu, K., Rodriguez, G. A., Zajc, M., Jacquemin, E., Clement, M., De Coster, A., \& Lambot, S. (2019). A new drone-borne GPR for soil 
moisture mapping. Remote Sensing of Environment, 235, 111456. doi: 10.1016/j.rse.2019.111456

Yoder, R. E., Freeland, R. S., Ammons, J. T., \& Leonard, L. L. (2001). Mapping agricultural fields with GPR and EMI to identify offsite movement of agrochemicals. Journal of Applied Geophysics, 47(3-4), 251-259. doi: 10.1016/s0926-9851(01)00069-6

Yuan, Z. Y., \& Chen, H. Y. H. (2013). Effects of Disturbance on Fine Root Dynamics in the Boreal Forests of Northern Ontario, Canada. Ecosystems, 16(3), 467-477. doi: 10.2307/23501472

Zenone, T., Morelli, G., Teobaldelli, M., Fischanger, F., Matteucci, M., Sordini, M., Armani, A., Ferre, C., Chiti, T. \& Seufert, G. (2008). Preliminary use of ground-penetrating radar and electrical resistivity tomography to study tree roots in pine forests and poplar plantations. Functional Plant Biology, 35(9-10), 1047-1058. doi: $10.1071 /$ fp08062
Manuscrito recibido el 14 de mayo de 2020

Aceptado el 19 de junio de 2020

Publicado el 9 de julio de 2021

\section{Este documento se debe citar como:}

Rodríguez-Robles, U., \& Arredondo Moreno, J. T. (2021). Geofísica para la prospección agrícola y forestal: guía para interpretar imágenes del subsuelo. Madera y Bosques, 27(1), e2712172. doi: 10.21829/myb.2021.2712172

Madera y Bosques por Instituto de Ecología, A.C. se distribuye bajo una Licencia Creative Commons Atribución-NoComercialCompartirlgual 4.0 Internacional. 